\title{
TAXONOMIA DE APENESIA (HYMENOPTERA, BETHYLIDAE) NA RESERVA BIOLÓGICA DE DUAS BOCAS, ESPÍRITO SANTO, BRASIL
}

\author{
Michelle Silva Corrêa ${ }^{1,2}$ \\ Celso Oliveira Azevedo ${ }^{1}$
}

\begin{abstract}
TAXONOMY OF APENESIA (HYMENOPTERA, BETHYLIDAE) IN THE RESERVA BIOLÓGICA DE DUAS BOCAS, ESPÍRITO SANTO, BRAZIL. The new species Apenesia stricta, A. concavata, A. unipilosa, A. distincta and A. fusilis, from Reserva Biológica de Duas Bocas, Espírito Santo, Brazil, are described and illustrated. Additional specimens of $A$. transversa Evans, 1963 are examined, species variation analyzed and new distribution data added.
\end{abstract}

KEYWORDS. Apenesia, Bethylidae, Brazil, Hymenoptera, Pristocerinae.

\section{INTRODUÇÃO}

Apenesia Westwood, 1874 (Pristocerinae) possui cerca de 130 espécies, particularmente abundante na Região Neotropical com 70 espécies (GORDH \& MOCZAR, 1990). No Brasil são citadas 26 espécies ocorrendo nos estados do Amazonas, Pará, Rio de Janeiro, Minas Gerais, Mato Grosso, São Paulo, Santa Catarina e Rio Grande do Sul. Neste trabalho, são descritas cinco espécies do Espírito Santo, elevando para 31 o número de espécies conhecidas para a fauna brasileira. Dados gerais da biologia do gênero indicam que suas espécies são parasitóides de larvas de Coleoptera (EvANs, 1963; KIEFFER, 1914).

O material examinado pertence à Coleção Entomológica da Universidade Federal do Espírito Santo (UFES). A nomenclatura adotada neste estudo segue Evans (1963) e as abreviaturas das medidas e índices utilizados foram: comprimento da asa anterior

\footnotetext{
1. Universidade Federal do Espírito Santo, Departamento de Biologia, Av. Marechal Campos 1468, Maruípe, 29.040-090 Vitória, ES, Brasil. (mcorrea@escelsa.com.br; cazevedo@npd.ufes.br)

2. Bolsista de Iniciação Científica PIBIC/CNPq-UFES.
} 
(LFW); comprimento da cabeça (LH); largura da cabeça (WH); largura da fronte (WF); comprimento do olho (HE); linha ocelar-ocular (OOL); largura do triângulo ocelar (WOT); diâmetro do ocelo anterior (DAO); linha vértice-ocular (VOL). A nomenclatura do integumento segue HARRIS (1979).

\section{Apenesia stricta sp. nov.}

(Figs. 1-4)

Macho. Comprimento 7,6 mm; LFW 4,35 mm. Cabeça e mesosomo pretos; gáster castanho-escuro; mandíbulas e antenas castanhas; flagelômero distal mais escuro; pernas, palpos e tégulas castanho-claras; asas subhialinas.

Cabeça (fig. 1): mandíbula com 5 dentes apicais pontiagudos, o basal maior (fig. 2). Clípeo com lobo mediano estreito e truncado (fig. 3), com uma carena mediana completa, reta no perfil. Quatro primeiros segmentos antenais na razão de 20:09:20:18; segmento III 3,33 x mais longo que largo; segmento XI 2,38 x mais longo que largo; pubescência flagelar subereta, pêlos um pouco mais longos que a metade do diâmetro do segmento. Olhos com pêlos muito esparsos. Fronte polida, pontuações muito pequenas e esparsas. WH/LH 1,04; WF/HE 1,4; OOL/WOT 1,42; ângulo frontal do triângulo ocelar agudo; distância do topo do ocelo posterior à crista do vértice 0,61 x DAO. Vértice amplamente arredondado. VOL/HE 0,75.

Mesosomo (fig. 1): pronoto polido com carena transversal anterior; mesoscuto polido; notáulices incompletas anteriormente. Disco propodeal 1,06 x mais largo que longo, com carena média e transversal posterior distintas; triângulo basal desenvolvido; lados do propódeo levemente estriados; declividade estriada. Mesopleura polida, com poucas pontuações.

Metasomo com longo pecíolo. Hipopígio com margem posterior côncava e dente um pouco menor que a placa. Genitália (fig. 4): parâmero com base curta, cerca de um terço do comprimento do parâmero, muito estreita, com dilatação angulada interna, ápice subquadrado, muito largo, cerca de 2,5 x mais longo que a base, a margem apical côncava, canto superior interno inclinado, pêlos principalmente concentrados na porção superior interna; volsela com o ramo dorsal do dígito com os pêlos da margem interna maiores do que as do ápice, uniformemente espesso, ápice arredondado, mais alto do que a margem basal do ápice do parâmero, basivolsela com alguns pêlos internos; edeago uniformemente espesso, mais alto que a margem basal do ápice do parâmero, projeção mediana pequena, um par de lobos laterais dorsais arredondados e membranosos, e um par lateral ventral com uma projeção filamentosa direcionada para dentro.

Material-tipo. Holótipo o', BRASIL, Espírito Santo: Cariacica, Reserva Biológica de Duas Bocas, 10.X.1996, E. H. Freitas col., varredura de vegetação (UFES). Parátipos: 19 ', mesma localidade do holótipo, 2.VIII-10.X.1996, C. O. Azevedo \& H. S. Sá col., varredura de vegetação (UFES).

Variações. Antenas mais escuras; clípeo um pouco triangular, talvez pela presença da carena média, muito marcada.

Observações. Apenesia stricta pertence ao grupo brasiliensis e é semelhante a $A$. tarascana Evans, 1963 do México por ter os lobos laterais do edeago um pouco maiores do que o mediano, mas em A. stricta a cúspide um pouco menor e mais larga e o lobo lateral do parâmero mais evidente.

Etimologia. Nome referente ao lobo mediano do edeago mais curto do que os laterais. 

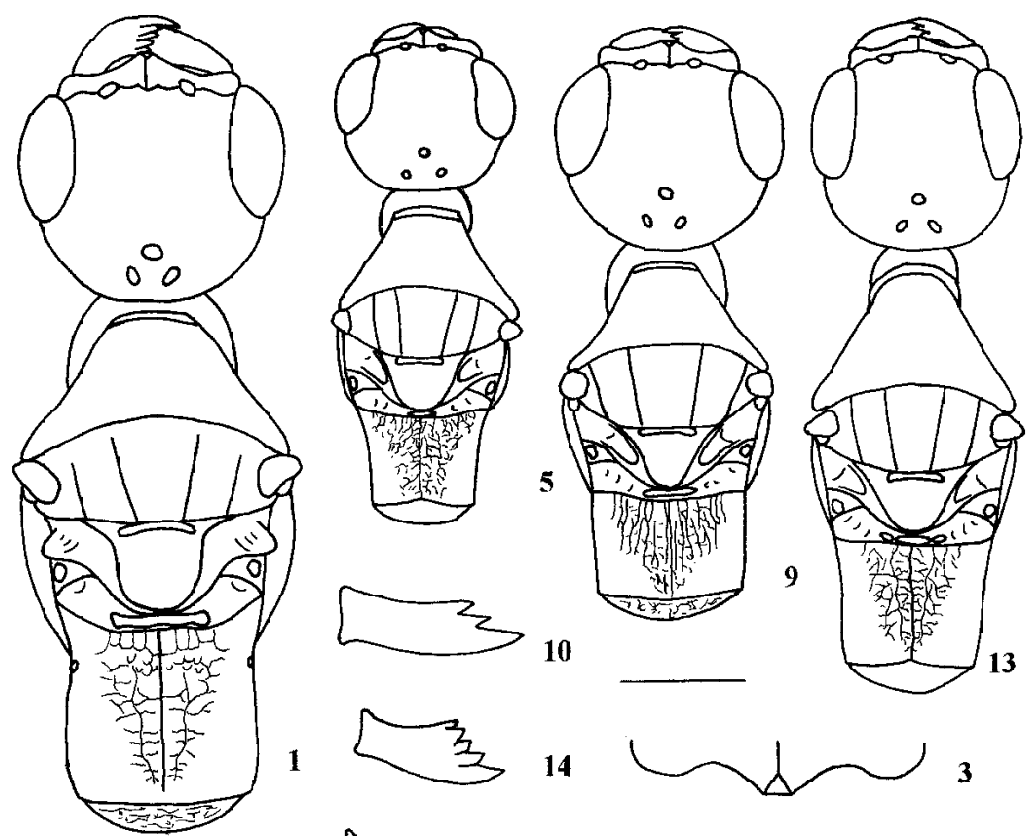

14
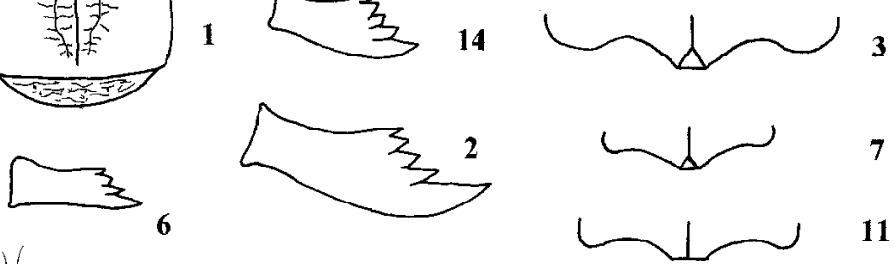

6
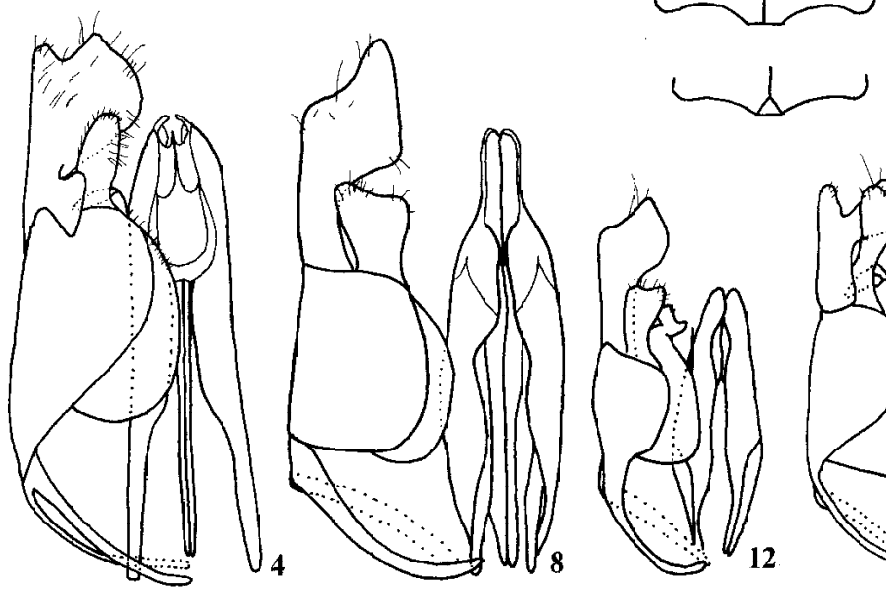

15

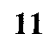

11
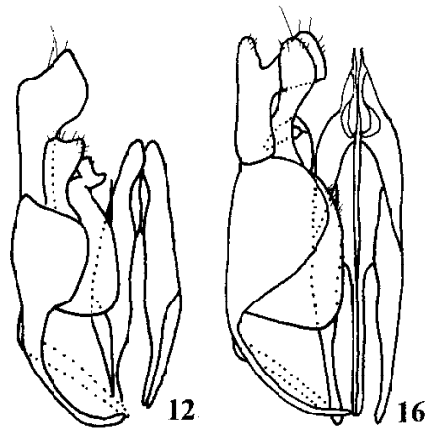

Fig. 1-16. 1-4. Apenesia stricta sp. nov.: 1, cabeça e mesosomo, dorsal; 2, mandíbula, frontal; 3, clípeo, dorsal; 4 , genitália, ventral. 5-8. Apenesia concavata sp. nov.: 5, cabeça e mesosomo, dorsal; 6, mandíbula, frontal; 7 , clípeo, dorsal; 8, genitália, ventral. 9-12. Apenesia unipilosa sp. nov.: 9, cabeça e mesosomo, dorsal; 10, mandíbula, frontal; 11, clípeo, dorsal; 12, genitália, ventral. 13-16. Apenesia distincta sp. nov.: 13, cabeça e mesosomo, dorsal; 14, mandíbula, frontal; 15, clípeo, dorsal; 16, genitália, ventral. Figs. 1, 5, 9, 13, escala 0,21 mm; figs. 2, 3, $6,7,10,11,14,15$, escala $0,32 \mathrm{~mm}$; figs. $4,12,16$, escala $123 \mu \mathrm{m}$; fig. 8 , escala $246 \mu \mathrm{m}$. 


\section{Apenesia transversa Evans, 1963}

Espécie do grupo brasiliensis, conhecida apenas a partir do holótipo do Rio de Janeiro, é aqui citada pela primeira vez para o Espírito Santo. Os exemplares examinados variam na densidade dos pêlos e na profundidade das pontuações.

Material examinado. BRASIL, Espírito Santo: Cariacica, Reserva Biológica de Duas Bocas, 42 , 09.IX.1996-25.III.1997, C. O. Azevedo, E. H. Freitas \& H. S. Sá col., varredura de vegetação (UFES).

\section{Apenesia concavata sp. nov.}

(Figs. 5-8)

Macho: comprimento 3,8 mm; LFW 2,4 mm. Cabeça e mesosomo pretos; gáster castanho-escuro; antenas, tégulas, mandíbulas, palpos e pernas castanho-claras; asas subhialinas.

Cabeça (fig.5): mandíbula com 4 dentes (fig.6). Clípeo com lobo mediano truncado (fig.7), carena mediana completa, reta no perfil. Quatro primeiros segmentos antenais na razão de 13:07:07:06; segmento III 2,33 x mais longo que largo; segmento XI duas x mais longo que largo; pubescência flagelar subereta, pêlos um pouco mais curtos que a metade da largura do segmento, face ventral dos primeros flagelômeros com cerdas eretas maiores. Olhos com pêlos esparsos. Fronte coriácea, fracamente pontuada; WH/LH 1,07; WF/WH 1,66; WF/HE 1,17; OOL/WOT 1,08; ângulo frontal do triângulo ocelar agudo; distância do topo do ocelo posterior à crista do vértice $0,88 \times \mathrm{DAO}$. Vértice em arco retilíneo sobre os olhos, cantos amplamente arredondados. VOL/HE 0,57.

Mesosomo (fig.5): pronoto coriáceo, pontuado; carena transversal anterior desenvolvida; notáulices completas. Disco propodeal 1,21 x mais largo que longo; carena transversal posterior presente; triângulo basal característico, formado por linhas paralelas à carena medial do disco propodeal; lados do propódeo e declividade estriados. Mesopleura coriácea, pilosa; calo glabro, pouco desenvolvido.

Metasomo séssil. Hipopígio com margem posterior levemente côncava, dente pouco menor que a placa. Genitália (fig. 8): parâmero com base estreita, quase metade da largura do ápice do parâmero, ápice subquadrado, largo, com a margem apical côncava, canto superior interno com uma projeção triangular, margem interna reta, cantos arredondados, alguns pêlos acompanhando a margem apical e no canto inferior do ápice; volsela com ramo ventral do dígito dilatado, margem apical ligeiramente côncava e pilosa, tão alta quanto a margem apical do ápice do parâmero, basivolsela glabra; edeago com ápice mais estreito, um pouco mais alto que a margem basal do ápice do parâmero, com um par de lobos arredondados.

Material-tipo. Holótipo ơ, BRASIL, Espírito Santo: Cariacica, Reserva Biológica de Duas Bocas, 29.X.1996, C. O. Azevedo col., varredura de vegetação (UFES). Parátipos: 78 on', mesma localidade do holótipo, 26.VII.1996-25.II.1997, C. O. Azevedo, E. H. Freitas \& H. S. Sá col., varredura de vegetação (UFES).

Variações. Comprimento do corpo menor; fronte um pouco mais coreácea; cabeça mais alongada, pilosidade mais intensa; declividade do propódeo mais estriada.

Observações. Apenesia concavata pertence ao grupo mexicana, e é semelhante a A. inca Evans, 1963 por possuir ápice do ramo ventral do dígito muito largo, porém possui mandíbulas com quatro dentes, margens apicais do parâmero e do ramo ventral do dígito côncavas, e lobo apical do edeago sem constrição basal. 
Etimologia. Nome referente às margens apicais do parâmero e ramo venral do dígito côncavas.

\section{Apenesia unipilosa sp. nov.}

(Figs. 9-12)

Macho. Comprimento 4,95 mm; LFW 2,95 mm. Cabeça e mesosomo pretos; gáster castanho-escuro; antenas, tégulas, mandíbulas, palpos e pernas castanho-claras; asas subhialinas.

Cabeça (fig. 9): mandíbula com 3 dentes, basal desenvolvido (fig. 10). Clípeo com lobo mediano estreito e truncado (fig. 11), carena mediana completa, reta no perfil. Quatro primeiros segmentos antenais na razão de 15:05:09:07; segmento III 1,8 x mais longo que largo; segmento XI 1,75 x mais longo que largo; pubescência flagelar subereta, menor que a metade da largura do segmento. Olhos com pêlos muito esparsos. Fronte coriácea, pontuações bem marcadas. WH/LH 0,98; WF/WH 1,6; WF/HE 1,12; OOL/ WOT 1,25; ângulo frontal do triângulo ocelar agudo; distância do topo do ocelo posterior à crista do vértice 0,59 x DAO. Vértice amplamente arredondado. VOL/HE 0,63.

Mesosomo (fig.9): pronoto coriáceo; carena transversal anterior presente; notáulices completas. Disco propodeal 1,12 x mais largo que longo; carena transversal posterior presente, bem marcada; carena discal mediana distinta; triângulo basal desenvolvido; lados do propódeo e declividade estriados. Mesopleura coriácea, pouco pilosa; calo pouco desenvolvido; sulco mesopleural marcado.

Metasomo séssil. Hipopígio com margem posterior reta, dente mais ou menos do mesmo tamanho que a placa. Genitália (fig.12): parâmero com base estreita, cerca de metade da largura e comprimento do parâmero, ápice sublosangular, canto superior interno ligeiramente projetado, subangulado e com poucos pêlos, canto inferior interno amplamente arredondado, margem interna reta; volsela com ramo ventral do dígito um pouco dilatado, ápice ligeiramente côncavo e piloso, menor que a margem basal do ápice do parâmero, basivolsela com 1-2 pêlos longos; edeago uniformemente espesso, com um par de lobos um pouco largos e arredondados, ápice menor que a margem basal do ápice do parâmero.

Material-tipo. Holótipo ơ, BRASIL, Espírito Santo: Cariacica, Reserva Biológica de Duas Bocas, 24.IX.1996, C. O. Azevedo col., varredura de vegetação (UFES).

Observações. Apenesia unipilosa é do grupo mexicana, e é semelhante a A. inca, mas difere desta por apresentar o ramo ventral do dígito não tão dilatado, base da volsela possui um pêlo distinto e lobos apicais uniformemente largos.

Etimologia. Nome referente ao pêlo distinto da basivolsela.

\section{Apenesia distincta sp. nov.}

(Figs. 13-16)

Macho. Comprimento 3,85 mm; LFW 2,85 mm. Cabeça e mesosomo pretos; gáster castanho-escuro; mandíbulas e antenas castanhas; flagelômero distal mais escuro; tégulas, palpos e pernas castanho-claras; asas subhialinas.

Cabeça (fig.13): mandíbula com 5 dentes (fig.14). Clípeo com lobo mediano estreito e truncado (fig.15), carena mediana completa, reta no perfil. Quatro primeiros segmentos antenais na razão de 16:05:07:10; segmento III 3,33 x mais longo que largo; segmento 
XI 5 x mais longo que largo; pubescência flagelar subereta, menor que a largura do segmento. Olhos glabros. Fronte coriácea, pontuações pequenas. WH/LH 1,05; WF/ WH 1,64; WF/HE 1,27; OOL/WOT 1,33; ângulo frontal do triângulo ocelar agudo; distância do topo do ocelo posterior à crista do vértice $0,55 \mathrm{x}$ DAO. Vértice amplamente arredondado. VOL/HE 0,65.

Mesosomo (fig.13): pronoto coriáceo, piloso, fracamente pontuado; carena transversal anterior presente; notáulices completas. Disco propodeal 1,04 x mais largo que longo; carena transversal posterior ausente; carena discal mediana completa; triângulo basal desenvolvido; lados do propódeo polidos e declividade estriada. Mesopleura coriácea, pouco pontuada; calo e sulco pouco desenvolvidos.

Metasomo séssil. Hipopígio com margem posterior um pouco arredondada, dente quase do mesmo tamanho da placa. Genitália (fig. 16): parâmero com base estreita, um terço da largura e cerca de metade do comprimento do ápice, ápice sub-retangular, cantos arredondados, margem apical fortemente côncava, margens basal e interna do ápice, retas; volsela com ramo ventral do dígito um pouco dilatado, ápice arredondado e piloso, alcançando a margem apical do ápice do parâmero, basivolsela com poucos pêlos; edeago uniformemente espesso, ápice estreito, um pouco menor que a margem apical do ápice do parâmero, um par de lobos que se estreitam até o ápice, terminando em filamentos.

Material-tipo. Holótipo ơ, BRASIL, Espírito Santo: Cariacica, Reserva Biológica de Duas Bocas, 06.II.1997, H. S. Sá col., varredura de vegetação (UFES). Parátipo ơ', mesmos dados do holótipo, exceto 22.X.1996 (UFES).

Variações. Antenas castanho-claras.

Observações. Apenesia distincta, do grupo mexicana, difere bastante das demais espécies deste grupo por ter cúspides longas, tão altas quanto o parâmero e ter o edeago com ápice muito fino e longo, atingindo também a altura do ápice do parâmero.

Etimologia. Nome referente ao fato da espécie ser muito diferente das demais do seu grupo.

\section{Apenesia fusilis sp. nov.}

(Figs. 17-20)

Macho. Comprimento 6,25 mm; LFW 3,9 mm. Cabeça, mesosomo e gáster pretos; antenas castanho-claras, pedicelo castanho; tégulas e palpos castanho-claros; mandíbulas pretas; pernas castanho-escuras; asas subhialinas.

Cabeça (fig.17): mandíbula com 5 dentes, o basal maior (fig.18). Clípeo com lobo mediano arredondado, com uma carena mediana completa, reta no perfil (fig.19). Quatro primeiros segmentos antenais na razão de 24:07:14:13; segmento III 2,33 x mais longo que largo; segmento XI 3,25 x mais longo que largo; pubescência flagelar subereta, menor que a metade da largura, com cerdas eretas, esparsas, um pouco maiores que os da pubescência. Olhos glabros. Fronte polida, muito pontuada; WH/LH 0,98; WF/WH 1,7; WF/HE 1,13; OOL/WOT 1,13; ângulo frontal do triângulo ocelar agudo; distância do topo do ocelo posterior à crista do vértice 2,7 x DAO. Vértice amplamente arredondado. VOL/HE 0,63.

Mesosomo (fig.17): pronoto polido, piloso; carena transversal anterior ausente; notáulices incompletas anteriormente. Disco propodeal tão longo quanto largo, com as carenas mediana e transversal posterior distintas; triângulo basal bem desenvolvido. 


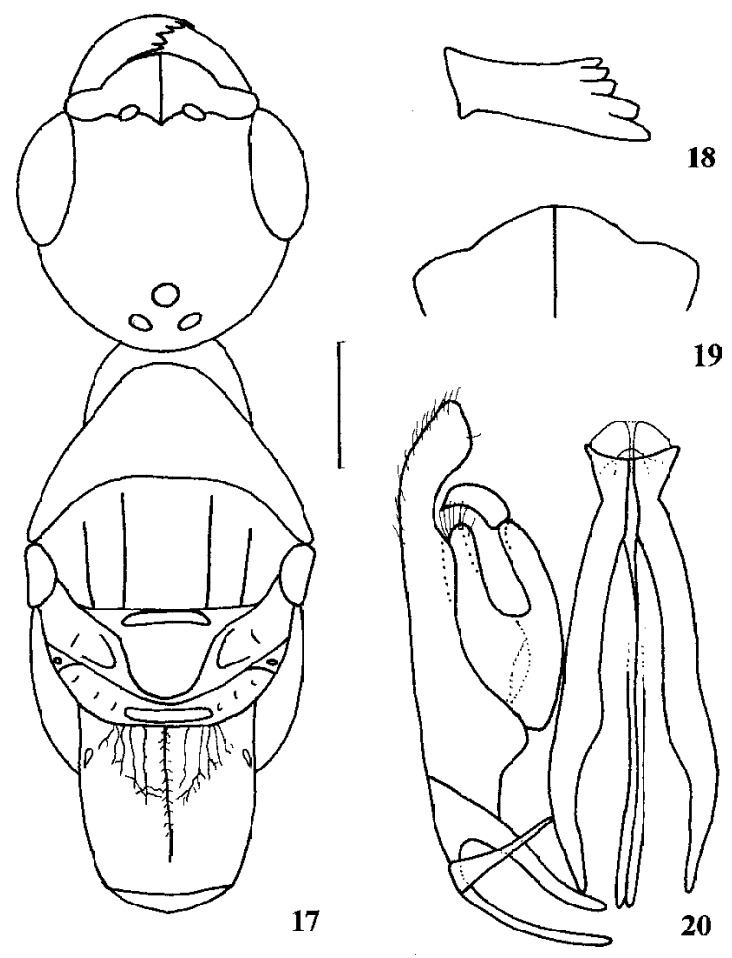

Fig. 17-20. Apenesia fusilis sp. nov.: 17, cabeça e mesosomo, dorsal; 18, mandíbula, frontal; 19, clípeo, dorsal; 20, genitália, ventral. Fig. 17 , escala $0,21 \mathrm{~mm}$; figs. 18,19 , escala $0,32 \mathrm{~mm}$; fig. 20 , escala $123 \mu \mathrm{m}$.

Mesopleura pilosa, exceto na região do calo, glabro, pouco evidente; sulco mesopleural pouco desenvolvido.

Metasomo séssil. Hipopígio: margem posterior côncava e dente tão longo quanto a placa. Genitália (fig. 20): parâmero com base estreita, menor $2 \mathrm{x}$ a largura do ápice, pouco dilatado e piloso na margem apical, cantos arredondados, margens interna reta e basal côncava, parâmero fundido ao basiparâmero; volsela com ramo ventral do dígito um pouco menor que a margem basal do ápice do parâmero, ápice pouco dilatado, curto, piloso no ápice arredondado; edeago um pouco mais baixo que o ápice do parâmero, com espessamento gradativo até um estreitamento no ápice que apresenta um par de lobos dilatados, com o ápice ligeiramente côncavo, e um par de projeções membranosas arredondadas.

Material-tipo. Holótipo ơ, BRASIL, Espírito Santo: Cariacica, Reserva Biológica de Duas Bocas, 09.IX.1996, C. O. Azevedo col., varredura de vegetação (UFES). Parátipos: 30 ơ', mesma localidade do holótipo, 27.VIII.1996-25.III.1997, C. O. Azevedo, E. H. Freitas \& H. Santos Sá col., varredura de vegetação (UFES).

Variações. Pontuações mais profundas; cabeça ligeiramente menor.

Observações. Apenesia fusilis pertence ao grupo pilicornis, mas difere não só de todas as espécies do grupo, como também das demais de Bethylidae por ter o parâmero 
totalmente fundido ao basiparâmero.

Etimologia. Nome refere-se ao parâmero totalmente fundido ao basiparâmero.

Agradecimentos. Ao setor de Genética (UFES), pelo empréstimo da câmara-clara do microscópio para ilustração das genitálias.

\section{REFERÊNCIAS BIBLIOGRÁFICAS}

Evans, H. E. 1963. A Revision of the Apenesia in the Americas (Hymenoptera, Bethylidae). Bull. Mus. comp. Zool., Cambridge, Mass., 130(4): 249-359.

Harris, R. A. 1979. A glossary of surface sculpturing. Occas. Pap. Ent., Sacramento, 28:1-31.

Gordh, G. \& Moczar, L. 1990. A catalog of the world Bethylidae (Hymenoptera). Mem. Am. ent. Inst., Gainesville, 46: 1-364.

KIEFFER, J. J. 1914. Bethylinae. Das Tierreich, Berlin, 41: 228-595. 